\section{Rotating a discriminant analysis solution}

\section{JOHN D. MORRIS \\ Georgia Southern College, Statesboro, Georgia 30458}

Some disagreement has arisen in respect to the data matrix most suitable for the interpretation of the psychological construct nature of discriminant functions derived in a multiple discriminant analysis. While several authors suggest that the matrix of standardized weights on the constituent data-level variables (pattern) should be analyzed to derive function names (Klecka, 1975; Morrison, 1967; Tatsuoka, 1971), other authors suggest that these weights are inferior because of their semipartial nature and/or because of lack of sampling stability (Cooley \& Lohnes, 1971; Darlington, Weinberg, \& Walberg, 1973; Huberty, 1975; Veldman, 1967). In a factor analytic tradition, the variable-function correlation matrix (structure) has therefore been suggested as an alternative for interpretation.

There is also some controversy (Cooley \& Lohnes, 1971; Huberty, 1975; Tatsuoka, 1973) concerning the interpretational utility of rotating these discriminant functions to achieve greater psychological meaningfulness. Moreover, a problem similar to that described in the unrotated state occurs when deciding whether to rotate the pattern or structure matrix. It has been suggested that rotation of either the pattern or structure should be used largely experimentally as empirical experience is gained (Klecka, 1975; Huberty, 1975; Tatsuoka, 1973).

In a review of commonly available computer programs, the only option found allowing the rotation of a discriminant analysis solution limited the user to rotating the pattern matrix (Klecka, 1975). The purpose of the present paper is to describe a computer program which rotates a pattern or structure matrix from a multiple discriminant analysis yielding two or more factors to the varimax criterion, hopefully facilitating the suggested experimental use of these procedures.

Description. The program rotates either an input pattern or structure matrix to the varimax criterion. Since this rotation is accomplished through a subroutine constructed from a combination of two currently available varimax subroutines (Guertin \& Bailey, 1970; Veldman, 1967), other orthogonal rotational schemes can easily be substituted as a subroutine unit.

When a matrix is entered, the alternate unrotated matrix is calculated; one determines the other. After the input matrix is rotated, the alternate rotated matrix is also output. Whether a pattern or structure matrix is input and varimax rotated, the output includes the unrotated pattern and structure and the rotated pattern and structure. But rotation is independent of groups, and can be carried out without knowledge of the groups' characteristics if such centroid information is not of interest. Liberal program dimensions limit variables to 70 , discriminant functions to 5 , and groups to 10 . These are easily altered should the user desire.

Input. The user must enter the number of variables, the number of discriminant functions, a parameter identifying whether the structure or pattern matrix is being input, the variable intercorrelation or covariance matrix, and the structure or pattern matrix to be rotated. If centroid information is also to be generated, the number of groups and the groups' data-level variable means must be entered. If the variable correlation rather than covariance matrix is input, the variable standard deviation must be entered so that the necessary variable covariance matrix may be created.

Output. Contingent upon data entered, program output includes the unrotated and varimax rotated structure, pattern, and centroids.

Computer and language. This FORTRAN IV program has been used both on a CDC CYBER 74 (in both batch and interactive modes) and an IBM 370/165.

Availability. The program, with complete documentation and sample input and output, is available at no cost from the author at: Department of School Services, Box 8143, Georgia Southern College, Statesboro, Georgia 30458.

\section{REFERENCES}

COOley, W. W., \& LoHnes, P. R. Multivariate data analysis. New York: John Wiley, 1971.

Darlington, R. B., Weinberg, S. L., \& Walberg, H. J. Canonical variate analysis and related techniques. Review of Educational Research, 1973, 43, 433-454.

Guertin, W. H., \& Balley, J. P. Introduction to modern factor analysis. Ann Arbor, Mich: Edwards Brothers, 1970.

HuberTy. C. J. Discriminant analysis. Review of Educational Research, 1975, 45, 543-598.

KLECKA, W. R. Discriminant analysis. In N. H. Nie, C. H. Hull, J. G. Jenkins, K. Steinbrenner, \& D. H. Bent (Eds.), Statistical package for the social sciences (2nd ed.). New York: McGraw-Hill, 1975.

MoRRISON, D. F. Multivariate statistical methods. New York: McGraw-Hill, 1967.

Tatsuoka, M. M. Multivariate analysis. New York: John Wiley, 1971.

Tatsuoka, M. M. Multivariate analysis in educational research. In F. N. Kerlinger (Ed.) Review of research in education. Itasca, Ill: Peacock, 1973.

VELDMAN, D. J. Fortran programming for the behavioral sciences. New York: Holt, Rinehart, \& Winston, 1967. 